\title{
High flow nasal cannula oxygen therapy versus non-invasive ventilation for chronic obstructive pulmonary disease with acute-moderate hypercapnic respiratory failure: an observational cohort study [Corrigendum]
}

Sun J, Li Y, Ling B, Zhu Q, Hu Y, Tan D, Geng P, Xu J. Int J Chron Obstruct Pulmon Dis. 2019;14:1229-1237.

The author has advised that an error occurred in the numbering of the second and third affiliations in the affiliations list. The correct affiliations list for this paper should appear as follows:

Jiayan Sun, ${ }^{1}$ Yujie Li, ${ }^{1}$ Bingyu Ling, ${ }^{1}$ Qingcheng Zhu, ${ }^{1}$ Yingying $\mathrm{Hu},{ }^{2}$ Dingyu Tan, ${ }^{1}$ Ping Geng, ${ }^{1}$ Jun $\mathrm{Xu}^{3}$
${ }^{1}$ Department of Emergency, Clinical Medical College, Yangzhou University, Northern Jiangsu People's Hospital, Yangzhou, People's Republic of China; ${ }^{2}$ Department of Emergency, The First Affiliated Hospital and College of Clinical Medicine of Henan University of Science and Technology, Luoyang, People's Republic of China; ${ }^{3}$ Department of Emergency, Peking Union Medical College Hospital, Chinese Academy of Medical Sciences, Beijing, People's Republic of China

\section{Publish your work in this journal}

The International Journal of COPD is an international, peer-reviewed journal of therapeutics and pharmacology focusing on concise rapid reporting of clinical studies and reviews in COPD. Special focus is given to the pathophysiological processes underlying the disease, intervention programs, patient focused education, and self management protocols. This journal is indexed on PubMed Central, MedLine and CAS. The manuscript management system is completely online and includes a very quick and fair peer-review system, which is all easy to use. Visit http://www.dovepress.com/testimonials.php to read real quotes from published authors. 